\title{
Estimation of cell membrane properties and erythrocyte red-ox balance in patients with metabolic syndrome
}

\author{
Edward Kowalczyk • Jan Kowalski • \\ Jan Błaszczyk • Lukasz Gwoździński • \\ Julita Ciećwierz $\cdot$ Monika Sienkiewicz
}

Received: 3 February 2012/ Accepted: 1 October 2012/Published online: 8 October 2012

(C) The Author(s) 2012. This article is published with open access at Springerlink.com

\begin{abstract}
Metabolic syndrome (MS) is associated with occurrence of the many cardiovascular risk factors such as atherogenic dyslipidemia, visceral fat distribution, arterial hypertension and pro-thrombotic and pro-inflammatory status. In our study the effect of disorders that appear in MS on red-ox balance and erythrocyte cell membrane properties were estimated. The study comprised 50 patients with diagnosed MS and in 25 healthy subjects. Content of thiobarbituric acid reactive substances (TBARS) and catalase, superoxide dismutase and glutathione peroxidase activity were estimated in red blood cells. Moreover, conformation status of membrane proteins, membrane fluidity and osmotic fragility were evaluated. MS was found to manifest: (1) the increase of the concentration of TBARS in erythrocytes with no statistically significant differences in antioxidant enzymes activity, (2) disorders in the structure of erythrocyte cytoskeleton proteins, (3) the increase in membrane lipids fluidity at the depth of 5th and 12th carbon atom of fatty acid hydrocarbon chain and significantly decreased fluidity at the depth of 16th carbon atom, (4) increased erythrocyte osmotic fragility.
\end{abstract}

E. Kowalczyk · J. Ciećwierz

Department of Pharmacology and Toxicology, Medical

University of Lodz, Lodz, Poland

J. Kowalski

Department of Internal Medicine and Cardiac Rehabilitation, Medical University of Lodz, Lodz, Poland

J. Błaszczyk · Ł. Gwoździński

Department of Basis and Pre-Clinical Sciences,

Medical University of Lodz, Lodz, Poland

M. Sienkiewicz $(\bowtie)$

Department of Medical and Sanitary Microbiology,

Medical University of Lodz, pl. Hallera 1, 90-647 Lodz, Poland

e-mail: monika.sienkiewicz@umed.lodz.pl
Keywords Metabolic syndrome $\cdot$ Erythrocytes $\cdot$ Cell membranes · Red-ox balance

\section{Introduction}

Numerous clinical and epidemiological observations related to metabolic syndrome (MS) result in more and more frequent molecular as well as pathophysiological and therapeutical investigations that concern especially the nature of the relation between obesity, diabetes mellitus Type 2, arterial hypertension, dyslipidemia and atherosclerotic process and its cardiovascular complications [1]. Endothelial dysfunction is thought to play a crucial role in the progression of atherosclerotic changes.

Oxidative stress related to hypertension, diabetes mellitus and hypercholesterolemia are among factors that cause endothelial damage [2-4]. In an early stage of atherogenesis enhanced adhesive molecules expression, increased adhesion and chemotaxis of monocytes, lymphocytes and platelets are observed [5, 6]. Many published prospective studies stated [7-10], that the risk of cardiovascular complications in atherotrombosis is proportional to the degree of endothelial dysfunction. It seems that red cells in addiction to endothelium can imply atherosclerotic complications. An important feature of an erythrocyte is its viscoelasticity that is its ability of changing shape but its volume remains unchanged [11, 12]. This ability depends among others on red cell shape, membrane fluidity and internal cell viscosity [13-15]. Normal structure of plasmatic membrane of erythrocytes conditions their most important functions: membrane enzymes activity, transport of ions and non-ionic substances, osmotic stability, oxygen diffusion, membrane receptors activity. Decreased erythrocyte viscoelasticity leads to blood flow impairment and worsening of tissue perfusion $[13,16]$. 
The aim of the study was to determine cell membrane properties and erythrocyte red-ox balance in patients with MS.

\section{Material}

The study comprised 50 so far untreated patients ( 24 women and 26 men), aged 18-75 years (mean 55.9-11.82 years), with MS, hospitalized at the Department of Internal Medicine and Cardiac Rehabilitation, Teaching Hospital No:5 in Lodz. MS was defined according to NCEP/ATPIII [17] criteria and was diagnosed when three or more risk factors were present: central obesity (circumference of waist at the umbilical level: men $>102 \mathrm{~cm}$, women $>88 \mathrm{~cm}$; serum triglycerides $>150 \mathrm{mg} / \mathrm{dl}$ or treatment; serum HDL-cholesterol concentration (HDL-C): men $<40 \mathrm{mg} / \mathrm{dl}$, women $<50 \mathrm{mg} / \mathrm{dl}$ or treatment; blood pressure $\geq 130 / 85 \mathrm{~mm} \mathrm{Hg}$ or treatment; fasting glycemia $\geq 110 \mathrm{mg} / \mathrm{dl}$ or treatment).

The control group consisted of 25 healthy subjects (12 women and 13 men) comparable as regards age (mean $54.24 \pm 12.84$ years).

All the study population gave their informed consent for the inclusion into the study. The study was approved by the Bioethics Committee of Medical University in Lodz, No: RNN/257/05/KB from June 26, 2005.

Characteristics of patients with MS taking a part in the study. The group of patients with MS demonstrated the most frequent occurrence of visceral obesity $(92 \%)$ followed by arterial hypertension (86\%), increased triglycerides concentration (72\%), fasting hyperglycemia (48\%), while the most seldom observed component was decreased HDL-C (44\%).

Visceral obesity occurred significantly more frequently than increased triglycerides and glucose levels and decreased HDL-C. Hypertriglycerydemia was observed significantly more often in comparison to the increased glucose and reduced HDL-Cs. Prevalence of elevated blood pressure was significantly more frequent than increased glucose and decreased HDL-Cs.

In the study group, the highest percentage (44\%) were patients with four MS components. Three of the components were found in $40 \%$ of patients, while the presence of all five components was shown in $16 \%$ of patients.

All patients with MS presented high cardiovascular death risk ( $\geq 5 \%$ ) determined according to SCORE algorithm.

\section{Methods}

Preparation of erythrocytes

Whole blood was centrifuged and plasma as well leukocyte layer, were removed. The remaining erythrocyte suspension was washed three times with ice-cold PBS solution of $\mathrm{pH} 7.4$ and centrifuged at 3,500 rpm for $10 \mathrm{~min}$ (Sigma $3 \mathrm{k} 15$ ). Then, a suspension of $50 \%$ hematocrit value was obtained for studied erythrocytes.

\section{Isolation of erythrocyte membranes}

Erythrocyte membranes were isolated with the modified method of Dodge [18]. Erythrocyte suspension was lysed using $20 \mathrm{mmol} / \mathrm{l}$ using phosphate buffer of $\mathrm{pH} 7.4$ and centrifuged. Then, the procedure was repeated using the same solution of the concentration 10 and $5 \mathrm{mmol} / \mathrm{l}$ in order to wash off the hemoglobin from the erythrocyte ghosts.

Physical state of membrane proteins

Conformation changes of membrane proteins were estimated with the electron paramagnetic resonance method using MSL and ISL spin labels. $2 \mu \mathrm{l}$ of both labels in ethanol solution were added to $1 \mathrm{ml}$ of erythrocyte membrane suspension and the samples were incubated at $4{ }^{\circ} \mathrm{C}$ for $60 \mathrm{~min}$. The excess of not bound label was washed out with ice-cold PBS solution of $\mathrm{pH}$ 7.4, until EPR signal disappeared.

The ratio $h_{\mathrm{w}} / h_{\mathrm{s}}\left(h_{\mathrm{w}}\right.$ - the height of the amplitude of a line from the population of weakly immobilized spin label residue of label to the height of amplitude of strongly immobilized component $-h_{\mathrm{s}}$ ) was calculated from the obtained spectra of MSL attached to membrane proteins. In case of ISL the mobility of label bound to proteins was calculated as the relative rotation correlation time $\tau_{\mathrm{c}}[19-21]$ from the equation:

$\tau_{\mathrm{c}}=k w_{0}\left[\left(\frac{h_{0}}{h_{-1}}\right)^{-\frac{1}{2}}-1\right]$

where: $k-6.5 \times 10^{-10}, w_{0}$-width of middle line of EPR spectrum, $h_{0}$-height of middle line of EPR spectrum, $h_{-1^{-}}$ height of high-field line of EPR spectrum.

Analysis of erythrocyte membrane fluidity

Fluidity of erythrocyte lipid bilayer was estimated by electron paramagnetic resonance method using fatty acids doxyl derivatives $(5,12,16$-doxylstearic) as spin labels. $1 \mu \mathrm{l}$ of each label in ethanol was added into $1 \mathrm{ml}$ of erythrocyte suspension samples and then incubated for $30 \mathrm{~min}$ at room temperature. The ethanol concentration in erythrocyte suspension did not exceed $0.1 \%$.

Spectra were obtained for all three labels and the ratio of the height of the low-field line amplitude $\left(h_{+1}\right)$ to the height of the middle line amplitude $\left(h_{0}\right)$ was calculated $[8,9]$. The measurements were performed at room temperature with Bruker ESP 3000E apparatus [20, 21]. 
Determination of erythrocyte osmotic fragility

Erythrocyte osmotic fragility was determined by spectrophotometric method with the use of Beckman DV 650 apparatus. Red blood cells suspension was added to the $\mathrm{NaCl}$ solution of decreasing molar concentration: from 150 to $55 \mathrm{mmol} / \mathrm{l}$. Absorbance measurement was performed in a supernatant at the wave length $540 \mathrm{~nm}$. The percentage of hemoglobin was calculated from the equation:

$H \%=\frac{A_{\mathrm{x}}-A_{0}}{A_{\mathrm{w}}-A_{0}} \times 100 \%$

where: $A_{\mathrm{x}}$-sample absorbance, $A_{0}$-absorbance for physiological concentration $\mathrm{NaCl}=155 \mathrm{mmol} / \mathrm{l}, A_{\mathrm{w}}$-absorbance after total erythrocyte hemolysis in distilled water.

Parameter $\mathrm{C}_{50}$, indicating $\mathrm{NaCl}$ concentration in which there comes to hemolysis of $50 \%$ of erythrocytes, was calculated from the obtained curves of osmotic fragility.

\section{Antioxidative enzymes}

Erythrocyte MDA concentration was measured according to Placer et al. method [22]. Erythrocyte SOD-1 activity was determined according to the method of Misra and Fridovich [23]. Erythrocyte GSH-Px activity was measured according to the method of Little et al. [24] using coumene hydroperoxide as a substrate. Erythrocyte catalase (CAT) activity was measured according to Beers et al. [25].

\section{Statistical analysis}

The obtained results were subjected to statistical analysis using $t$-Student and Mann-Whitney tests. The testing was performed at the level of significance $p<0.05$.

\section{Results}

Two labels, maleimide (MSL) and iodoacetamide (ISL), covalently bound to protein thiol groups, mainly of the spectrin/actin complex were used to investigate physical status of membrane proteins. The ratio of $h_{\mathrm{w}} / h_{\mathrm{s}}$ was calculated from EPR spectra of MSL attached to membrane protein. This parameter is a sensitive indicator of protein physical state. In the study group erythrocytes the decrease of this parameter was observed as compared to the controls (statistically significant differences) (Fig. 1).

Changes in membrane proteins structure were also observed in the case of iodoacetamide label. Statistically significant differences in the rotational correlation time of the label bound to membrane proteins are shown in Fig. 2.
Three spin labeled fatty acids 5-DS, 12-DS and 16-DS, having paramagnetic group at different carbon atoms of hydrocarbon chain, were used to estimate erythrocyte lipid membrane fluidity. The ratio of the height of low field amplitude to the height of the spectrum middle line $\left(h_{+1} / h_{0}\right)$ was calculated from spectra of labeled fatty acids incorporated to lipid membrane. The obtained results (Fig. 3) demonstrated statistically significant increase in the ratio $h_{+1} / h_{0}$ for label 5-DS and 12-DS. In the case of 16-DS label significantly decreased fluidity was observed.

The erythrocyte osmotic fragility was also investigated in patients and in the control group. Our study demonstrated the decrease of $\mathrm{C}_{50}$ parameter in the study group (statistically significant differences). The results are presented in Fig. 4.

In patients with MS statistically significant increase of TBARS content was observed in erythrocytes, while there were no significant changes in antioxidant enzymes activity: CAT, superoxide dismutase (SOD) and glutathione peroxidase (GPX).

Parameters of red-ox balance of erythrocytes in patients and controls are presented in Table 1.

\section{Discussion}

Many previous studies have proved that free radical-mediated reactions are one of the main biochemical mechanisms responsible for initiation and progression of early atherosclerotic changes. These reactions lead to lipoprotein oxidative modification and marked changes in cells, that are involved it atherogenic process [26-30]. Red cells are particularly exposed to free radical action, because as molecular oxygen transporters they are a potential source of reactive oxygen species. In physiological conditions about $0.5-3 \%$ hemoglobin is oxidized daily to met-hemoglobin, which is

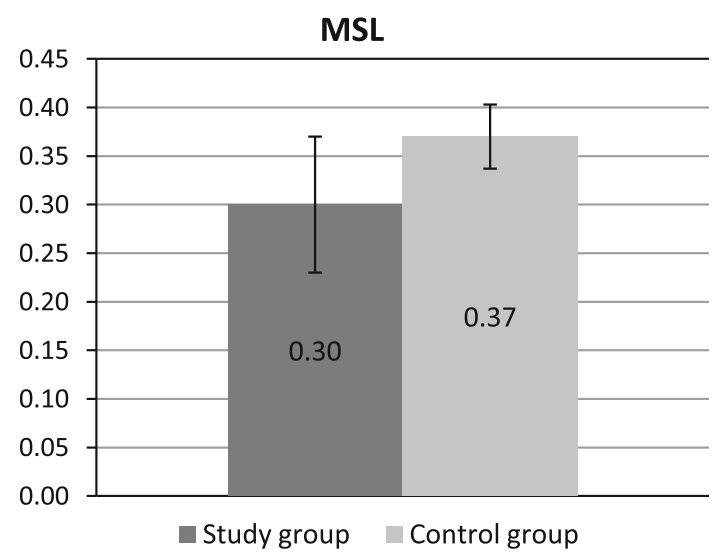

Fig. $1 \mathrm{H}_{\mathrm{w}} / \mathrm{h}_{\mathrm{s}}$ parameter of maleimide label (MSL) bound to control erythrocyte membranes and erythrocytes from patients with metabolic syndrome. Means with standard deviations are presented 
ISL

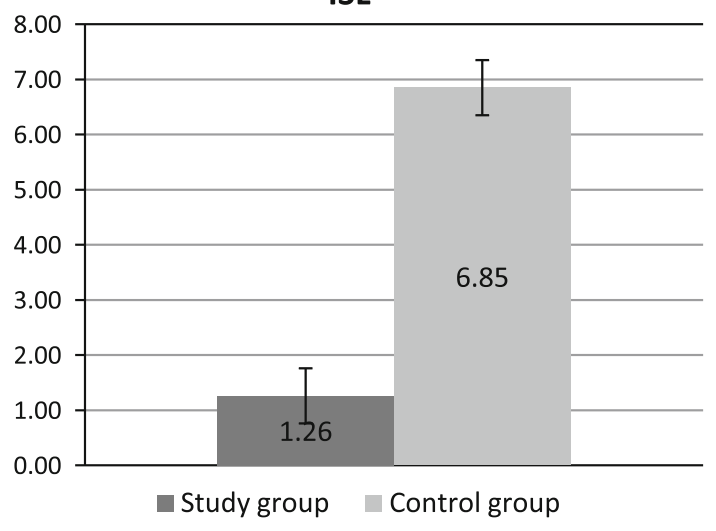

Fig. 2 Differences in the rotational correlation time $\left(\tau_{\mathrm{c}}\right)$ of iodoacetamide label (ISL) bound to erythrocyte membrane proteins between study and control group. Means with standard deviations are presented

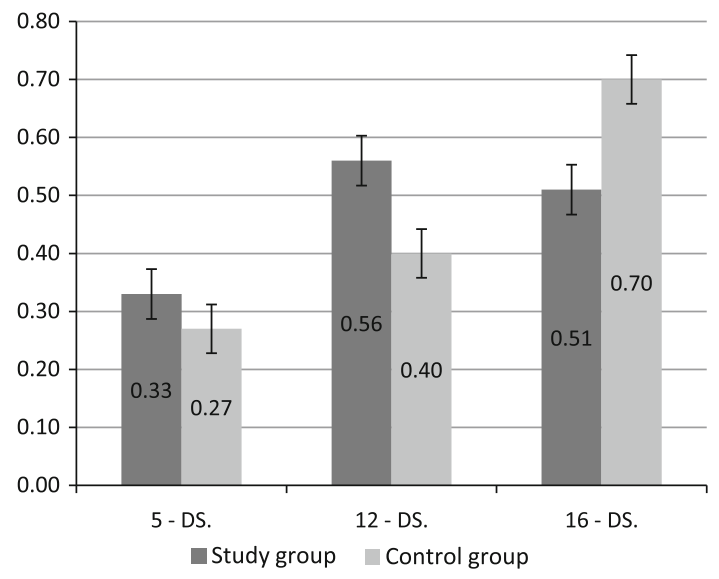

Fig. 3 Parameter $h_{+1} / h_{0}$ for 5-DS, 12-DS and 16-DS labels incorporated into erythrocyte membrane lipids in control and study group. Means and standard deviations are presented

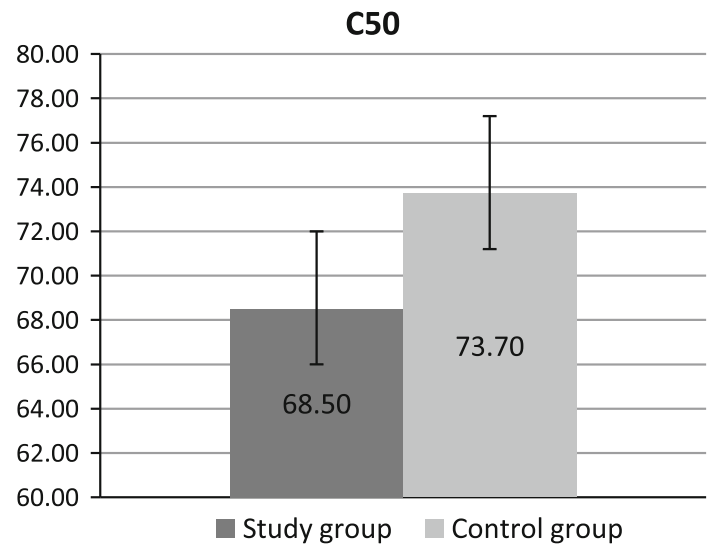

Fig. 4 Parameter $\mathrm{C}_{50}$ changes in erythrocytes in patients and controls. Means and standard deviations are presented

associated with superoxide free radical release. Moreover, erythrocyte cell membranes contain a lot of polyunsaturated fatty acids, which in environment rich in oxygen and oxygenderived radicals are oxidized to lipid superoxides. Erythrocytes possess multiple enzymatic and non-enzymatic defence mechanisms to prevent peroxidation reactions, however during oxidative stress they become exhausted. Erythrocyte TBARS concentration can be the indicator of peroxidation intensity in these cells because majority of TBARS are peroxidation end-products such as malondialdehyde [30]. Jayakumari et al. observed in patients with stable and unstable angina increased erythrocyte TBARS concentration in comparison to healthy subjects. The concentration of oxidized peroxidation products depended on ischemic heart disease severity and coexisting risk factors. The highest peroxidation products concentration was found in patients with concomitant hiperlipidemia, diabetes mellitus and subsequently in heavy smokers and patients with arterial hypertension. In our study the $60 \%$ increase of erythrocyte TBARS concentration was observed in patients with MS, in comparison with the control group. It may be supposed, that red cell susceptibility to free radical activity is intensified in patients with MS. The results of Simon et al. [31] in vitro studies were the confirmation of this hypothesis. They investigated erythrocytes from severe asymptomatic hypercholestrolemic men and they proved increased reactivity of red cells to AAPH-2,2'-azobis, 2 -amidinopropane hydrochloride-azo-complex, that undergoes complete destruction generating at a constant rate water soluble superoxide radicals. The investigators used two parameters that characterize susceptibility of erythrocytes to oxidation: (a) lag-time (LT)-time necessary for the induction of lipid oxidation; (b) $\mathrm{T}_{50}$-time needed for the initiation of erythrocyte hemolysis in $50 \%$ of cases. The statistically significant LT and $\mathrm{T}_{50}$ shortening was demonstrated in erythrocytes of hypercholesterolemic patients in comparison to the controls. Basing on Simon's studies [31-33] it was hypothesized, that elevated erythrocyte susceptibility to reactive oxygen species activity in the early stage of oxidative stress resulted mainly from decreased vitamin $\mathrm{E}$ content in cells. Similar results were obtained when susceptibility to lipoprotein LDL oxidation was investigated [29]. In our study vitamin E concentration was not evaluated, but we estimated antioxidative enzymes activity: CAT, SOD and GPX. We noted insignificant increase in the activity of these enzymes, however markedly elevated activity was observed in the younger age group (20-30 years) and markedly lower (even as compared to the control group) in the older age group (about 70 years). This observation can confirm the antioxidant system exhaustion in these patients followed by the increase of peroxidation products-TBARS. The majority of investigators postulate, that lipid peroxidation decreases lipid fluidity and stiffens the membrane [34]. In the conditions of increased free radical generation, as it happens in atherosclerosis, MDA and 4-hydroxynoneal concentration increases in plasma and in vessel wall [35]. Lipid peroxidation products can modify 
Table 1 Red-ox balance of erythrocytes

$N S$ no significance

\begin{tabular}{lllll}
\hline Group & $\begin{array}{l}\text { TBARS } \\
(\mu \mathrm{mol} / \mathrm{gHb})\end{array}$ & $\begin{array}{l}\text { CAT } \\
(\mathrm{U} / \mathrm{Hb})\end{array}$ & \multicolumn{1}{l}{$\begin{array}{l}\text { SOD } \\
(\mathrm{U} / \mathrm{gHb})\end{array}$} & $\begin{array}{l}\text { GSHPx } \\
(\mathrm{U} / \mathrm{gHb})\end{array}$ \\
\hline Control & $0.22 \pm 0.05$ & $12.9 \pm 2.6$ & $2182 \pm .5481 .5$ & $36.4 \pm 4.6$ \\
MS & $0.36 \pm 0.08$ & $14.6 \pm 4.3$ & $2588.6 \pm 521.8$ & $37.2 \pm 3.8$ \\
Statistical significance & $p<0.05$ & $\mathrm{NS}$ & $\mathrm{NS}$ & $\mathrm{NS}$ \\
\hline
\end{tabular}

physical properties of cell membranes contributing to cell dysfunctions [8]. Introduction of polar superoxide, ketone aldehyde or hydroxide groups into the regions of phospholipid molecules which are localized in the inner side of the lipid bilayer decreases hydrophobicity of the interior of a lipid bilayer membrane and changes bilayer structure. Then there increases in nonspecific the membrane permeability to hydrogen ions and other polar substances for which the lipid bilayer interior is a barrier difficult to pass. Peroxidation decreases electric potential differences on both sides of the membranes (depolarizes them), disturb lipid membrane asymmetry leading to phosphatidylserine exposition on plasmatic membrane outer surface. In normal conditions phosphatidylserine is only kept on the inner-leaflet, the cytosolic side, of cell membranes [36, 37]. Lipid peroxidation causes also inhibition of the activity of membrane enzymes and transporting proteins e.g. $\left(\mathrm{Ca}^{+2}, \mathrm{Mg}^{+2}\right)$ ATP-ase (calcium pump), $\mathrm{Na}^{+} \mathrm{K}^{+}$(sodium-potassium pump) [37]. In our study apart from changes in red-ox balance, conformation changes in membrane cytoskeleton proteins as well as in membrane lipid fluidity and erythrocytes osmotic fragility were found in patients with MS. Conformation status pf membrane cytoskeleton proteins and membrane lipid fluidity affect erythrocyte shape, size and osmotic fragility. In the study on the conformation of membrane proteins, mainly spectrin/actin complex two spin label (MSL, ISL) were used. EPR spectra of protein bound labels point to the disturbances in the structure of erythrocyte cytoskeleton proteins in patients that can result from oxidative stress and/or changed proteinlipid interactions. These can be conformation changes of protein structure and/or oxidation of thiol groups which are most susceptible to oxidation. Modifications in spectrin/actin complex may affect the membrane cytoskeleton structure. The differences in membrane protein structure observed in the study group can be related to the increase in membrane lipid fluidity at the depth of 5 th and 12 th carbon atom of fatty acid hydrocarbon chain that shows the modification of polar parts of phospholipids in surface and hydrophobic region of lipid membrane cell monolayer (a half of monolayer). The increase in erythrocyte membrane lipid fluidity was also observed in model studies with $t$-butyl hydroperoxide which initiates peroxidation process [38]. Then, marked decrease in membrane lipid fluidity was observed at the depth of 16th carbon atom spin probe. Most likely disturbances of erythrocyte cell membrane fluidity at different lipid monolayer depth observed in our study resulted from changes in proteins/lipids interactions and/or membrane lipid peroxidation as well as differences in their composition. Changes in the structure of plasmatic membrane components are reflected in erythrocyte osmotic fragility. Impaired erythrocytes osmotic fragility in patients with MS can result from enhanced cell membrane elasticity that is probably related to observed disturbances in membrane cytoskeleton protein structure and increase in lipid bilayer fluidity.

\section{Conclusions}

In patients with MS changes in erythrocytes red-ox balance and osmotic fragility as well as changes of membrane protein conformation status and erythrocyte cell membrane fluidity are observed.

Open Access This article is distributed under the terms of the Creative Commons Attribution License which permits any use, distribution, and reproduction in any medium, provided the original author(s) and the source are credited.

\section{References}

1. Achike FI, To N-HP, Wang H, Kwan CY (2011) Obesity, metabolic syndrome, adipocytes and vascular function: a holistic viewpoint. Clin Exp Pharmacol Physiol 38:1-10

2. Ross R (1999) Atherosclerosis-an inflammatory disease. N Engl J Med 340:115-126

3. Ross R (1993) The pathogenesis of atherosclerosis: a perspective for the 1990s. Nature 362:801-809

4. Katsuda S, Kaji T (2003) Atherosclerosis and extracellular matrix. J Atheroscler Thromb 10:267-274

5. Broncel M (2003) Inflammatory factors in atherosclerosis. Monit Ther Probl 14:77-84

6. Markuszewski L, Milczek P, Tyślerowicz P (2006) Predictive factors of acute coronary syndrome and restenosis. Overview. Kardiodiab 1:48-54

7. Heitzer T, Schlinzig T, Krohn K, Meinertz T, Munzel T (2001) Endothelial dysfunction, oxidative stress, and risk of cardiovascular events in patients with coronary artery disease. Circulation 104: 2673-2678

8. Suwaidi JA, Hamasaki S, Higano ST, Nishimura RA, Holmes DR, Lerman JA (2000) Long-term follow- up of patients with mild coronary artery disease and endothelial dysfunction. Circulation 101:948-954

9. Schachinger V, Britten MB, Zeiher AM (2000) Prognostic impact of coronary vasodilator dysfunction on adverse long-term outcome of coronary heart disease. Circulation 101:1899-1906 
10. Perticone F, Ceravolo R, Puija A, Ventura A, Glacopino S, Scozzafava A, Ferraro A, Chello AM, Mastroroberto P, Verdecchia P, Schillaci G (2001) Prognostic significance of endothelial dysfunction in hypertensive patients. Circulation 104:191-196

11. Shinitzky M (1984) Membrane fluidity in malignancy. Adversative and recuperative. Biochem Biophys Acta 738:251-261

12. Boesze-Battaglia K, Schimmel RJ (1997) Review cell membrane lipid composition and distribution: implications for cell function and lessons learned from photoreceptors and platelets. J Exp Biol 200:2927-2936

13. Chabanel A, Flamm M, Sung KL, Lee MM (1983) Influence of cholesterol content on red cell membrane viscoelasticity and fluidity. Biophys J 44:171-176

14. Muller S, Ziegler O, Donner M, Drouin P, Stoltz IF (1990) Rheological properties and membrane fluidity of red blood cells and platelets in primary hyperlipoproteinemia. Atherosclerosis 83: 231-237

15. Tsukada K, Sekizuka E, Oshio C, Minamitani H (2001) Direct measurement of erythrocyte deformability in diabetes mellitus with a transparent microchannel capillary model and high-speed video camera system. Microvasc Res 61:231-239

16. Schick BP, Schick PK (1985) Cholesterol exchange in platelets, erythrocytes and megakaryocytes. Biochim Biophys Acta 833: 281-290

17. Expert Panel on Detection, Evaluation, and Treatment of High Blood Cholesterol in Adults (2001) Executive Summary of the Third Report of the National Cholesterol Education Program (NCEP) Expert panel on detection, evaluation and treatment of high blood cholesterol in adults (Adult Treatment Panel III). JAMA 285:2486-2497

18. Dodge JT, Mitchell C, Hanahan DJ (1963) The preparation and chemical characteristics of hemoglobin-free ghosts of human erythrocytes. Arch Biochem Biophys 100:119-130

19. Gwoździński K (2000) Free radicals and electron spin resonance spectroscopy in biology and medicine. In: Ertel D (ed) Instrumental methods in biophysics and biomedical. Department of Applied Physics and Applied Mathematics, Technical University of Lodz, Lodz, pp 86-132

20. Płonka PM, Elas M (2002) Application of the electron paramagnetic resonance spectroscopy to modern biotechnology. Curr Top Biophys 26:175-189

21. Surewicz K (1978) Methods of interpretation of EPR spectra of spin-labeled biological membranes. Contemp Issues Biophys 3: 21-44

22. Placer ZA, Cushman LL, Johnson BC (1966) Estimation of product of lipid peroxidation malonyl dialdehyde) in biochemical systems. Anal Biochem 16:359-364
23. Misra HP, Fridovich J (1972) The role of superoxide anion in the autooxidation of epinephrine and a simple assay superoxide dismutase. J Biol Chem 247:3170-3175

24. Little C, O'Brien P (1968) An intracellular GSH peroxidase with a lipid peroxide substrate. Biochem Biophys Res Commun 31: $145-150$

25. Beers RF, Sizer IW (1952) A spectrophotometric method for measuring the breakdown of hydrogen peroxide by catalase. J Biol Chem 195:133-140

26. Ardlie NG, Selley ML, Simons LA (1989) Platelet activation by oxidatively modified low density lipoproteins. Atherosclerosis 76 : $117-124$

27. Aviram M (1996) Interaction of oxidized low density lipoproteins with macrophages in atherosclerosis and atherogenicity of antioxidants. Eur J Clin Chem Clin Biochem 34:599-608

28. Aviram M, Hussein O, Rosenblat M, Schlezinger S, Hayek T, Keidar S (1998) Interactions of platelets, macrophages and lipoproteins in hypercholesterolemia, antiatherogenic effects of HMG-CoA reductase inhibitor therapy. J Cardiovasc Pharmacol 31:39-45

29. Naruszewicz M (1999) The current view on the pathogenesis of atherosclerosis. Therapy 7:3-5

30. Jayakumari N, Ambikakumari V, Balakrishnan KG (1992) Antioxidant status in relation to free radical production during stable and unstable anginal syndromes. Atheroslerosis 94:83-190

31. Simon DL, Paul JL, Atger V (1998) Erythrocyte antioxidant status in asymptomatic hypercholesterolemic men. Atherosclerosis 13:375-381

32. Bierenbaum ML, Reichstein RP, Bhagavan HN, Watkins TR (1992) Relationship between serum lipid peroxidation products in hypercholesterolemic subjects and vitamin E status. Biochem Int 28:57-66

33. Lubin B, Chiu D (1982) Properties of vitamin E-deficient erythrocytes following peroxidant injury. Pediatr Res 16:928-932

34. Bartosz G (2003) Second face of oxygen. Free radical in nature, (in Polish). Polish Scientific, Warsaw

35. Chauhan V, Chauhan A (2010) Abnormalities in membrane lipids, membrane-associated proteins, and signal transduction in Autism. CRC, Boca Raton, pp 177-206

36. Jain SK, McVie R (1999) Hyperketonemia can increase lipid peroxidation and lower glutathione levels in human erythrocytes in vitro and in Type 1. Diabetes 48:1850-1855

37. Maridonneau L, Braquet P, Garay RP (1983) $\mathrm{Na}^{+}$and $\mathrm{K}^{+}$ transport damage by oxygen free radicals in human red cell membranes. J Biol Chem 258:3107-3113

38. Brzeszczyńska J, Gwoździński K (1998) Erythrocyte membrane damage induced by t-buthyl hydroperoxide. Curr Top Biophys 22(Suppl B):238-241 